\title{
Literatura, história e política - reflexões sobre um percurso crítico
}

\author{
Professor Dr. Benjamin Abdala Junior ${ }^{1}$
}

No livro Literatura, história e política, publicado em $1989^{2}$, procuramos estabelecer bases críticas para a circulação literária entre os países de língua portuguesa. Motivava-nos o estudo comparativo entre os escritores formados na atmosfera ideológica da frente popular antifascista, do período entre guerras, cujas produções continuaram depois, acompanhando as polarizações ideológicas da guerra fria. Esse livro, de certa maneira, constituiu ponto de convergência de uma formação iniciada em nossa graduação em Letras, nos finais dos anos 60, que trazia as marcas de situações de ditaduras, a do Brasil e também aquela do salazarismo. Estudar escritores empenhados era para nós uma forma de resistir à alienação e de contribuir para a reflexão crítica na universidade. Foi assim que iniciamos projeto de pósgraduação, em 1971, abordando a obra de Carlos de Oliveira, comparando-a com a de Graciliano Ramos, cujos resultados apareceram depois no trabalho A escrita neo-realista ${ }^{3}$.

A partir de Carlos de Oliveira, em termos de ensino da literatura portuguesa, viemos posteriormente ampliar nossos estudos para o conjunto dos escritores que a crítica portuguesa denominava de "neo-realistas". Entendíamos que este era um rótulo inapropriado para abarcar o conjunto dos escritores portugueses anti-salazaristas, com inclinação para o marxismo. Estudar escritores como Alves Redol, José Cardoso Pires, Manuel da Fonseca e tantos outros, era uma forma de denunciar o sufoco que vivíamos também em nosso país. Melhor ainda quando os relacionávamos com os escritores brasileiros, rotulados, também de forma insuficiente, de regionalistas.

Vieram depois os estímulos dos Cravos de Abril e da independência dos países africanos de língua oficial portuguesa, que tornaram, para nós, Portugal e os países africanos descolonizados, horizontes libertários para onde convergíamos nossas aspirações. Importava, nesse sentido, estabelecer bases para uma literatura comparada descolonizada. Um dos

\footnotetext{
${ }^{1}$ Universidade de São Paulo

${ }^{2}$ Literatura, história e política: literaturas de língua portuguesa no século XX. São Paulo, Ática, 1989.

${ }^{3}$ São Paulo: Ática, 1981 (Col. Ensaios, n. 73).
}

Revista Crioula USP, nº 17, junho de 2016 
primeiros enfrentamentos que tivemos foi com os próprios professores de literatura portuguesa, muito inclinados à visão mítica de um Portugal agrário, construída na perspectiva de um imaginário tradicional, próximo das idealizações dos migrantes portugueses provenientes de regiões rurais. Autores portugueses eram estudados nas universidades brasileiras, sobretudo, em suas possíveis relações empáticas com essas imagens passadiças, ao agrado da ideologia salazarista. Apontavam para um Portugal que existia em suas imaginações e que não figurava nas obras neo-realistas. Felizmente, essas inclinações provincianas já foram em parte descartadas ou atenuadas, embora ainda aflorem. Os hábitos antigos preservam-se no conservadorismo de certos nichos de poder.

Outro enfrentamento foi de ordem teórica e, sob este aspecto, encontramos respaldo crítico na renovação dos estudos de literatura comparada. Ao lado de outras restrições dos professores de literatura portuguesa, que insistiam em apontar perda de espaço nos currículos das universidades nas correlações que fazíamos entre escritores brasileiros e portugueses, também as tendências tradicionalistas da literatura comparada desconsideravam estudos feitos numa mesma língua. Interessavam-se pela circulação desencadeada por quem tinha poder simbólico, a partir do estatuto colonial e este não era o caso de Portugal, submetido à hegemonia de outros centros europeus. Sem desconsiderar formas de comparatismo que estudassem a atualização, no país, de repertórios provenientes dessa relação hegemônica, indispensáveis para a compreensão de facetas de cada uma dessas literaturas nacionais, procuramos enfatizar a necessidade de estudar as circulações internas e as articulações supranacionais que se faziam na ambiência de nosso comunitarismo cultural. Ao comparatismo radicado nessa situação de dependência em relação ao poder simbólico, um comparatismo que veio de nossa experiência histórica, relevamos a importância de desenvolvermos um outro que fosse pautado pelas articulações de solidariedade entre os atores de um campo intelectual supranacional. Solidariedade também associada às redes de circulação que se processou historicamente, na ambiência de nossa comunidade lingüística.

Estudamos, então, como se efetivavam os laços de solidariedade entre escritores que escreviam em português. E a nossa pesquisa, discutindo questões de literatura e política, centralizada nos autores engajados, alargou-se para a circulação que veio do comunitarismo cultural que aproxima os países de língua portuguesa. Assim, se antes havíamos estudado através de Carlos de Oliveira e Graciliano Ramos, tópicos de um neo-realismo paradigmático, alargamos esse estudo para a discussão do papel do escritor nessa circulação

Revista Crioula USP, nº 17, junho de 2016 
literária e cultural. Literatura, história e política, a publicação para onde convergiram essas reflexões, de estudo consagrado ao empenho do escritor, avançou a discussão para questões críticas mais gerais no âmbito desse comparatismo supranacional, embalado pela utopia libertária.

Nesses enlaces de solidariedade, procuramos dar destaque à emergência literária dos países africanos recentemente independentes do estatuto colonial. Mais do que o engajamento do cidadão-escritor, motivava-nos o engajamento que se configurava artisticamente numa forma nova, na palavra escrita, que se fazia ponto de encontro entre a vanguarda ideológica e a vanguarda literária. A análise do sentido político subjacente a essas produções da modernidade levou-nos a esboçar considerações sobre como essas formulações discursivas, em nível consciente ou inconsciente, se torna elemento estruturador do texto artístico. Preocupou-nos, sobretudo, estudar como os modos ideológicos de articulação soldam o discurso político ao literário, permitindo a discussão do caráter artístico do engajamento, do poder de linguagem subjacente ao texto, do circuito comunicativo e das articulações do campo intelectual em nossos países. Nesse estudo, procurávamos mostrar sempre como o tempo de plenitude sonhado pelo escritor participante tem significado literário se não se restringir a ser um mero "depois", mas colocar-se no texto como materialização de um debate mais amplo com a utopia.

Passadas hoje cerca de duas décadas dessa publicação, temos procurado rediscutir esses processos de modelização literária, formulados enquanto estratégias contra a hegemonia do capital industrial, reconfigurando-as diante da modalidade de uma outra forma de hegemonia capitalista: a do capital financeiro. Os escritores e a crítica das tendências engajadas do campo literário estavam voltados para os fios sociais organizados em torno dos estados nacionais. Em nosso trabalho sobre essas tendências, apontamos para a importância de se falar em português num mundo onde o inglês se tornara língua franca, tanto em termos culturais como de tecnologia. Logo em seguida, procuramos trazer outros laços para desenvolver estratégias contra o neoliberalismo da globalização, tendo por base os comunitarismos. Centrados no Brasil, enfatizamos perspectivas ibero-afro-americanas. Relevamos assim a região que os árabes chamaram de Al Andaluz, em sentido largo, abarcando Portugal - região de onde provieram os primeiros fluxos migratórios da América hispânica. Uma região híbrida para onde confluem as muitas culturas da bacia cultural mediterrânea. Região de agenciamentos culturais entre a Europa, África e Ásia. Um lócus 
híbrido que se torna ainda mais misturado nas interações ameríndias e com os povos africanos. Um lócus hoje à margem dos centros hegemônicos, que cria condições para perspectivas descentradas, tendo em vista reverter a assimetria da vetorização dos fluxos. E também hábitos culturais arraigados, mesmo em situação de aparente reciprocidade. Lembramos, para ilustrar, nesse sentido, um comentário do crítico cubano Roberto Fernando Retamar, que afirmava gostar de alguns críticos europeus que, de maneira simpática, diziam que o Caribe era o Mediterrâneo americano, mas que ficaria muito mais satisfeito se eles viessem a dizer que o Mediterrâneo era o Caribe europeu...

Foi assim que procuramos recuperar o sentido dos gestos dos escritores do novo humanismo que havíamos anteriormente estudado e as novas demandas que se colocam para uma literatura empenhada no competitivo mundo mercadológico desenhado pelo capitalismo financeiro. Como ler essa experiência histórica diante dessa nova modalidade de articulação econômico-social? Sob esse aspecto vale aqui uma observação: quando se fala em experiência histórica não se deve buscá-la apenas nos rastros do passado, mas nos gestos, às vezes sonhadores, que embalaram os percursos. Dessa forma, reconstruir o passado implica vê-lo como práxis de afirmação da potencialidade subjetiva e não apenas submissão a uma objetividade teoricamente construída ou imaginada. Ou como diz Antonio Machado, para valorizar horizontes ibéricos, no Canto XXIX, de Provérbios y cantares:
"Caminante, son tus huellas
el camino, y nada más;
caminante, no hay camino, se hace camino al andar.
$\mathrm{Al}$ andar se hace el camino, y al volver la vista atrás
se ve la senda que nunca
se ha de volver a pisar
Caminante, no hay camino, sino estelas en la mar."

No mar da vida, não há um caminho, mas estrelas que orientam ou estelas que simbolizam o caminhar. Olhar para trás implica ver marcas, padrões, que não se repetirão. Nesses caminhos, entretanto, poderíamos acrescentar, é possível divisar formas de práxis, que podem levar a inferir o sentido dos impulsos que motivaram atores de outras

\footnotetext{
${ }^{4}$ Poesias completas. Madrid: Espasa-Calpe, 1978. p. 200.
}

Revista Crioula USP, nº 17, junho de 2016 
configurações históricas. As práxis, em suas interações teoria e prática, consubstanciadas em projeto, vão definindo possíveis caminhos para quem não deixa de observar sulcos nas águas do mar ou instantâneos, sempre fulgurantes como tudo que está em movimento, como rastros de estrelas na água, cujas instáveis luzes se elevam no mar da vida.

O título de uma de nossas publicações procura para interatividades mais amplas: Fronteiras múltiplas, identidades plurais $^{5}$. À flexibilidade do capital financeiro, que se articula em rede, sempre substituindo distância por velocidade, procurávamos contrapor analogicamente articulações do campo intelectual, relevando suas imbricações supranacionais. Se há, na atualidade, um processo vertiginoso de estandardização dos produtos culturais por parte do mercado globalizador, que estabelece inclusive bases mercadológicas para a contestação do sistema (isto é, a administração da diferença), tornamse necessárias interativas articulações em rede, supranacionais, para fazer face não apenas à alienação numa inflexão da negatividade crítica, mas também positivamente para a continuidade dos sonhos e suas atualizações em gestos libertários que vieram dos escritores da década de 30 e das tendências que deram origem.

Ao contrário do que imaginavam parte desses escritores, não se justifica buscar fronteiras fechadas para o conhecimento, grupos étnicos ou para o Estado Nação. A tendência da globalização para um mundo sem fronteiras, não obstante, não implica desconsiderar a existência concreta desse mesmo estado e seus instrumentos de poder, que continuavam e continuam a atuar na vida social. Mais, os estados voltados para o conjunto de sua rede social poderiam desempenhar papéis efetivos nessas articulações supranacionais inclinadas ao comunitário. Mesmo em processo de debilitamento, os estados ainda reúnem condições de formular e estabelecer agenciamentos políticos em favor da sociedade, tornando factível que as fronteiras nacionais possam se abrir ou fechar, de maneira a aparar assimetrias dos fluxos da globalização. Evidentemente, esse jogo complexo e problemático continua motivado pelo desejo de constituir formas de solidariedade entre os povos. Não se pode esquecer que as teorizações político-culturais afins da ideologia das corporações hegemônicas, não deixam de ter suas bases em determinados estados. E também das resistências à autodeterminação, devidas à continuidade acrítica de hábitos cristalizados, aquietados e imobilistas em sua afeição à condição de subalternidade.

\footnotetext{
5 São Paulo: Editora SENAC: São Paulo, 2002.
}

Revista Crioula USP, nº 17, junho de 2016 


\section{Ecologia cultural}

O conceito de ecologia cultural, formulado em Literatura, história e política, continua operacional para a discussão das interações sempre renováveis de matérias e campos discursivos diversos, que marcam a bacia cultural ibero-afro-americana. Por ecossistema, entendemos uma produtiva coexistência contraditória de pedaços de culturas diferentes, em processos contínuos de tensões, interações e mesclagens. Logo, como um ecossistema híbrido e aberto, que não se afina à previsibilidade homogeneizada dos produtos dos shoppings culturais, nem com seu corolário recessivo fincado em identidades míticas, isto é, construções cristalizadas, essencialistas, imaginadas desde o passado, por quem deteve os meios de fazer valer seu poder simbólico.

Não há sentido em se procurar rastrear pretensas culturas "puras" em estratégias de depuração, pois qualquer recorte do passado leva-nos, ao contrário, à evidência de que se trata de construções que legitimaram hegemonias sociais e de que tais construções ordenaram o diverso em função de interesses dominantes. Importa desideologizar esse repertório para liberar a experiência humana e social para novas atualizações. Tendo em conta que as configurações culturais são híbridas e apontam para várias temporalidades e espaços, importa convergir para elas redes discursivas que têm referenciais locais, regionais, nacionais, transnacionais. Melhor ainda, se relevados por referenciais comunitários, conforme estamos desenvolvendo. A imagem dessa complexa ecologia cultural leva-nos a um sujeito concreto, historicamente situado, e será a partir da configuração histórica desse sujeito que ele procurará acessar um mundo que se articula em rede.

Convém ainda não nos limitarmos à virtualidade das redes, pois os indivíduos ou grupos de indivíduos que têm vínculos presenciais definidos, com sentimento de pertencer a determinado espaço, constituem a esmagadora maioria da população. Não pertencem a uma minoritária elite cosmopolita, cuja ideologia procura fazer acreditar na universalidade do lócus privilegiado de uma utopia burguesa. A formação da sociedade atual seria, nessa utopia de classe, um ponto de chegada, abolindo-se a possibilidade de uma história posterior. Congelamento do tempo social, reiteração dos hábitos burgueses à escala universal. É assim, no embalo auto-referente desses modelos de pensamento, modelos de produção, que esse campo intelectual cosmopolita se imagina e procura naturalizar suas perspectivas político-

Revista Crioula USP, nº 17, junho de 2016 
culturais. Sua lógica desconsidera a potencialidade criativa que vem justamente da hibridez das interações dos produtos culturais, tendendo a relevar apenas os modelos articulatórios do capitalismo financeiro como único índice de valor.

Ao contrário dessas postulações que pasteurizam e indeterminam as diferenças, continua a ocorrer um anseio por um lugar, que é justamente o local físico de onde os indivíduos e grupos de indivíduos acessam ou julgam capazes de acessar o mundo. Voltamos assim às inclinações dos assim chamados neo-realistas, para quem era imprescindível situar sempre onde o indivíduo tinha seus pés e por onde circulava sua cabeça. A partir da consideração desse lócus, o método comparatista reúne condições de evidenciar, em estudos contrastivos, diferenças internas ao objeto considerado ou das redes supranacionais que com ele se imbricam. São diferenças identificadas com experiências históricas e diversidades culturais análogas, que se configuram mais especificamente entre os estados nacionais enlaçados em rede pelas articulações comunitárias, conforme estamos enfatizando. Podemos reler, assim, como exemplo, uma rede a envolver Brasil e Moçambique, como se observa no "Poema a Jorge Amado", de Noêmia de Sousa, onde os dois países são aproximados pelas diferenças e aspirações comuns:

"O cais...

O cais é um cais como muitos cais do mundo...

As estrelas também são iguais

às que se acendem nas noites baianas

de mistério e macumba...

(Que importa, afinal, se as gentes sejam moçambicanas

ou brasileiras, brancas ou negras?)

Jorge Amado, vem!

Aqui nesta povoação africana

o povo é o mesmo também

é irmão do povo marinheiro da baía, companheiro Jorge Amado, amigo do povo, da justiça e da liberdade! ${ }^{6}$,

Este poema de 1949 é revelador de como o repertório empenhado que Jorge Amado ajudou a construir, circulou entre os países de língua oficial portuguesa. Pode-se afirmar que o compartilhamento de um repertório cultural com múltiplos pontos de convergência permite a construção de poemas como o de Noêmia de Sousa, onde o local, o nacional e o étnico

\footnotetext{
${ }^{6}$ Sangue negro. Luanda: União dos Escritores Angolanos, 1988. p.136.
}

Revista Crioula USP, nº 17, junho de 2016 
confluem supranacionalmente para o comunitário, este imbricado no social. A circulação desse repertório se faz não apenas em relação a autores da mesma situação histórica. Graciliano Ramos, por exemplo,

No Brasil, Eça de Queirós sensibilizou as gerações literárias ligadas às novas tendências realistas que se firmaram no século XX. A adesão às perspectivas abertas pelo ficcionista português explicita-se, por exemplo, no artigo de Linhas tortas ${ }^{7}$, publicado no Jornal de Alagoas, de Maceió, em 1915, em que Graciliano Ramos reage com indignação à agressão ao monumento a Eça de Queirós, em Lisboa, justamente naquele em que aparece o subtítulo de A relíquia: "Sobre a nudez forte da verdade - o manto diáfano da fantasia". A empatia de Graciliano por Eça é tamanha que seu discurso crítico recobre o do ficcionista português tal como ele aparece no artigo "Idealismo e realismo", embora ele não o tivesse lido, pois foi publicado só em 1929. A diferença será a ênfase na experiência, por parte do ficcionista brasileiro, experiência creditada à teoria da práxis marxista, que coloca o homem como ser ontocriativo, isto é, como indivíduo que ao interagir com o mundo modela seus pensamentos e ações. Outra diferença virá do encurtamento da distância: tendo vivenciado de forma direta e intensa o ambiente de suas representações literárias, Graciliano procurará ainda reduzir a distância entre a perspectiva de seus narradores e esses dados referenciais.

Mais, essa distorção, enquanto efeito de realidade, será enfatizada quando Graciliano Ramos procurou adequar o mundo interno/externo de seus narradores com imagens literárias que lhes seriam próprias, no percurso que vai de Caetés (1933) a Angústia (1936), passando por São Bernardo $(1934)^{8}$, com base na práxis de suas personagens narradoras João Valério (Caetés), Paulo Honório (São Bernardo) e Luís da Silva (Angústia). Como Gonçalo Mendes Ramires, de A ilustre casa de Ramires, de Eça de Queirós, também essas personagens escrevem um livro, no plano da história, para buscar um equilíbrio interior através de um encurtamento das distâncias entre o romance que escrevem (texto referido) e aquele que elas vivenciam e nós lemos. Entretanto, o destino de cada uma dessas personagens será diferente das aspirações que a motivam a escrever essa narrativa embutida no romance (mise en

\footnotetext{
${ }^{7}$ RAMOS, Graciliano. São Paulo, Livraria Martins Editora, 1962. p. 14-17.

${ }^{8}$ Edições referidas neste estudo: Caetés. 8. ed. São Paulo, Livraria Martins Editora, 1969; São Bernardo. 8. ed. São Paulo, Livraria Martins Editora, 1967; Angústia. 13. ed. São Paulo, Livraria Martins Editora, 1971.
}

Revista Crioula USP, $\mathrm{n}^{\circ}$ 17, junho de 2016 
abîme). Se Eça parodia através de Gonçalo um estilo passadiço, essa personagem constrói a "moeda falsa" referida no artigo "Idealismo e realismo", terminando por fazer dela também uma moeda de troca de favores políticos. João Valério equilibra-se nesse enquadramento quando constata as simetrias entre a antropofagia dos índios e a prática competitiva burguesa. Entre devorar e ser devorado, dirá depois o ficcionista português Carlos de Oliveira, o melhor é ir afiando os dentes.

São Bernardo e Angústia já mostram uma transformação nessa adequação de Graciliano Ramos. Em São Bernardo, Graciliano pretendia escrever um livro em língua de sertanejo, conforme revela em carta a sua esposa Heloísa Ramos ${ }^{9}$. Nesse romance é ironizada a pretensão de Paulo Honório escrever um romance seguindo a práxis capitalista da divisão do trabalho e da apropriação do trabalho alheio. Ao final do romance, essa personagem problematiza sua auto-representação. Vê-se como um bicho, devido à brutalidade de sua práxis existencial e sua imagem é registrada à maneira cinematográfica:

Ponho a vela no castiçal, risco um fósforo e acendo-a. Sinto um arrepio. A lembrança de Madalena persegue-me (...) Foi esse modo de vida que me inutilizou. Sou um aleijado. Devo ter um coração miúdo, lacunas no cérebro, nervos diferentes dos nervos de outros homens. E um nariz enorme, uma boca enorme, dedos enormes ${ }^{10}$.

A luz bruxuleante da vela dá as bases materiais para a imagem da distorção expressionista. Podemos ver nessa deformação uma pintura de um Portinari, por exemplo, com as deformações que vêm da práxis social. Se em Portinari as personagens são proletárias, aqui ela se situa também na classe dominante. Como poderia dizer Graciliano Ramos, os atores desses setores também são reduzidos a "bichos". A alienação também os atinge. E a distorção opera-se simetricamente, modelando caracteres físicos com caracteres psicológicos.

Esse novo realismo na representação da personagem, que pressupõe a distorção reveladora, como nas pinturas de Portinari que ilustravam os livros de Graciliano Ramos, marcou igualmente as imagens cinematográficas numa tradição que veio de um Einsenstein.

${ }^{9}$ Cartas. Graciliano Ramos. Rio de Janeiro, Record, 1981.

${ }^{10}$ Op. Cit. p. 166-167.

Revista Crioula USP, nº 17, junho de 2016 
Essa tendência de se desvelar o fenomênico pela distorção de seus aspectos visíveis teve continuidade nos anos seguintes. Na série literária, como indicamos, houve a apropriação de Graciliano pelos ficcionistas de ênfase social de Portugal. Referimo-nos mais especificamente a Carlos de Oliveira, cuja admiração por Graciliano pode ser situada como correlata àquela que o ficcionista brasileiro nutria por Eça de Queirós. Se A ilustre casa de Ramires foi modelo de partida para os romances com narradores de primeira pessoa de Graciliano, São Bernardo desempenhará o mesmo papel para os romances Casa na duna (1943), Pequenos burgueses (1948) e Uma abelha na chuva (1953) ${ }^{11}$. Carlos de Oliveira utilizava politicamente o nome de guerra de uma das personagens de Graciliano Ramos: Casimiro, de São Bernardo, personagem que mantém certa analogia com Firmino, de Casa na duna. Visualizava talvez entre ele e a personagem de Graciliano um comportamento análogo, atores à margem dos centros de decisão, mas presentes pontualmente em situações de emergência. A ambiência desses romances é simétrica à de São Bernardo: a decadência da pequena propriedade em face da concentração econômica capitalista; personagens/atores sociais que mantêm entre si não apenas caracteres paradigmáticos correlatos, mas também nomes semelhantes, como Paulo Honório (São Bernardo) e Mariano Paulo (Casa na duna); o meio geográfico Nordeste/Gândara, etc.

O sentido da distorção que apontamos em Graciliano por referência ao modo de apreensão da realidade de Paulo Honório e Luís da Silva, em Carlos de Oliveira se explicita ainda mais, como se pode observar na voz de Dr. Neto, personagem de Uma abelha na chuva:

O reflexo trêmulo das chamas batia-lhes no rosto e desfigurava-os: os olhos do padre muito mais encovados, a cana do nariz mais torta e luzidia; as bochechas de D. Violante inchadas como se tivesse a boca cheia de ar; uma recôndida sensualidade nos lábios de D. Maria dos Prazeres; a palidez de Álvaro Silvestre a resvalar num amarelo de cidra e idiotia (...) $/$ À primeira vista, o gosto da razão científica tão arreigado no seu espírito não se coadunava bem com deduções dessa natureza. No entanto, pensando melhor, tais juízos partiam de argumentos consistentes: os tiques psicológicos e morais de cada um, por exemplo. Conhecia-os como as suas mãos, de modo que podia deduzir o seguinte sem se

\footnotetext{
${ }^{11}$ São as seguintes as edições de referência: Casa na duna. 4. ed. Lisboa, Publicações Dom Quixote, 1970; Uma abelha na chuva. 5. ed. Lisboa, Publicações Dom Quixote, 1971; Pequenos burgueses. 3. ed. Lisboa, Publicações Dom Quixote, 1970.
}

Revista Crioula USP, nº 17, junho de 2016 
atraiçoar: vê-los desfigurados é vê-los verdadeiros $(\ldots)^{12}$

Diante da assimetria dos fluxos globalizadores e do prestígio de seus enredamentos mercadológicos, é que temos reiterado a importância de laçadas comparatistas pela América Latina e pelos países de línguas portuguesa e espanhola. Seriam estratégias tendentes a construir conjuntos de rostos diferenciados, tais como eles se desenharam em nossas experiências históricas. Tais rostos híbridos, onde coexistem traços locais, regionais ou nacionais, tenderiam à construção de fronteiras múltiplas, não apenas para ações internas ao estado nacional, mas também externas. Em termos de globalização, essas ações não deixariam de serem marcadas por modelos de trabalho hegemônicos, cujos produtos enchem as prateleiras dos shoppings culturais, mas a resistência em relação aos movimentos desses fluxos permitirá ao comunitário não se reduzir a eles. Ao alargar-se do local ao supranacional, ele poderá valer-se da dinâmica dos novos fluxos estabelecidos configurando, em termos político-culturais, blocos que concertem ações interativas comuns.

\section{Hegemonia financeira e fluxos da globalização}

O movimento do capital financeiro, na atualidade, é bastante complexo e não permite a simples oposição dicotômica entre padronização e diversidade. A hegemonia dessa modalidade de capital opera de forma vertiginosa, em fluxos que diminuem continuadamente distâncias por velocidades. Ela se efetiva de forma altamente flexível, enredando e operando em seu favor a produção industrial. Essa flexibilidade deixa a assimetria globalizadora capaz de movimentos desdobráveis, para lucrar de alguma forma, conforme assinalamos num ensaio mais recente:

A consciência dessas potencialidades mercadológicas - entre a estandardização massificadora e a transformação da diferença em etiquetas predeterminadas - parece-nos ser um dos traços distintivos entre o que ocorre na atualidade globalizadora $e$ as perspectivas impositivas, tradicionais nos processos coloniais e imperiais dos séculos passados. O novo Império, ao administrar em escala planetária, estreita as distâncias como nunca ocorrera anteriormente, procurando levar em consideração as margens das diferenças, sempre de olho no mercado. Procura assim também atender a um consumidor mais resistente à padronização, ganhando-o desde as instâncias da produção do bem cultural. Se antes prevaleciam as lógicas produtivas mais circunscritas a possíveis interesses

12 5. ed. Lisboa, Publicações D. Quixote, 1971. p. 181-182.

Revista Crioula USP, nº 17, junho de 2016 
nacionais, agora se impõem critérios das corporações supranacionais. Essa inclinação para a transnacionalidade não impede, contudo, que as corporações continuem a ter suas bases em determinados territórios, que regulam, a seu favor, os fluxos econômicos. São esses os novos territórios sacralizados, identificados com o Bem, com a supernação umbilicalmente associada às corporações e suas agências de controle. Lá se encontram igualmente os monumentos da nova ordem e, através de agências como o FMI, a OMC, o Nafta, etc., além - é evidente - de Hollywood e sua fábrica de mitos: os paradigmas econômicos e os modelos simbólicos para o conjunto do planeta ${ }^{13}$.

Estratégias puramente nacionais, que embalaram a modernidade, parece-nos hoje, além de insuficientes, equivocadas do ponto de vista político. Se há perversidade no enfraquecimento das fronteiras dos estados nacionais por parte do poder imperial e sua economia de mercado, essa fragilidade pode ser importante para o melhor compartilhamento e interação entre laços comunitários supranacionais. Como estava em nosso horizonte uma perspectiva política confluente com a formação de blocos e de fronteiras de cooperação, não ficaríamos assim restritos apenas às áreas culturais, mas haveria confluência para ações solidárias mais abrangentes. Essas conformações em blocos podem permitir estabelecer campos de resistência ao mundo do capital financeiro, com sua vertiginosa lógica do lucro, aliando acumulação do capital e mudança especulativa.

\section{Agenciamentos comunitários e interações culturais}

Refletir sobre especificidades nacionais significava para nós, nos princípios dos anos 90 e continua a significar na atualidade, situá-las num processo de agenciamentos comunitários que têm um solo histórico. No Brasil, esse solo cultural é enfaticamente híbrido, pela presença dos povos ameríndios e africanos, além dos europeus. A pluralidade cultural dos asiáticos (Oriente Médio) também fez sentir seus efeitos desde os tempos coloniais; mais recentemente houve influxos migratórios desse continente. Tais interações levaram-nos à consideração de um complexo cultural híbrido, interativo, onde a cultura brasileira se alimenta produtivamente de pedaços de muitas culturas, sem deixar de sofrer os efeitos dos imbricamentos com os patterns hegemônicos nos fluxos culturais. Logo, seria importante destacar em nossa literatura esses instáveis processos de identificação, em cuja

\footnotetext{
${ }^{13}$ ABDALA JUNIOR, Benjamin. Fronteiras múltiplas, identidades plurais:um ensaio sobre mestiçagem e hibridismo cultural. São Paulo: Editora SENAC São Paulo, 2002. p. 18.
}

Revista Crioula USP, nº 17, junho de 2016 
dinâmica se efetuam contínuas atualizações dessas matérias culturais complexas. Procurávamos nos afastar, assim, dos espartilhos ideológicos de identidades míticas. Na voz de Carlos Drummond de Andrade, em “Camões: história, coração, linguagem”, encontramos:

"Dos heróis que cantaste, que restou senão a melodia do teu canto?

As armas em ferrugem se desfazem, os barões nos jazigos dizem nada.

É teu verso, teu rude e teu suave balanço de consoantes e vogais, teu ritmo de oceano sofreado que os lembra ainda e sempre lembrará. tu és a história que narraste, não o simples narrador. Ela persiste mais em teu poema que no tempo neutro, universal sepulcro da memória. ${ }^{14,}$

Em relação aos estudos comparados, nos limites da língua portuguesa, tratava-se de verificar, por exemplo, o que existia da cultura portuguesa ou das dos países africanos na literatura do Brasil; da cultura brasileira ou dos países africanos na literatura de Portugal; ou das culturas do Brasil e de Portugal nas literaturas africanas de língua portuguesa. Há um diálogo, embutido nas formas literárias que circulam entre os países de língua portuguesa. E, na circulação dessas formulações do imaginário, pode ser evidenciada, como no poema de Drummond, uma visão crítica do repertório que nos envolve. Nos tempos de polarização ideológica, Drummond teve posição ambígua. Às vezes se identificava com a perspectiva aberta por Manuel Bandeira e seu pasargadismo: Vou-me embora pra Pasárgada / lá sou amigo do rei. Apropriada em Cabo Verde pelo grupo de escritores organizados em torno da revista Claridade, o pasargadismo se fez corrente crítica, identificado com a situação da imigração, mas com um viés crítico: Essa saudade fina de Pasárgada é um veneno gostoso dentro de meu coração, dirá o poeta cabo-verdiano Osvaldo Alcântara. Ou numa reação explicitamente contra-ideológica, como no brado de Ovídio Martins: Gritarei, Berrarei, Matarei / Não vou para Pasárgada.

As formas literárias das culturas de língua portuguesa circulam, assim, permitindo a apropriação singular, com relevo histórico, de um imaginário intercambiado. Essa criticidade

${ }^{14}$ Apud ABDALA JUNIOR, Benjamin. Camões - épica e lírica. São Paulo: Editora Scipione, 1993. p. 62.

Revista Crioula USP, nº 17, junho de 2016 
reúne condições de ser mais apurada pela intersecção dessas outras experiências históricas. Em Drummond, no diálogo entre as culturas brasileiras e portuguesas, há uma apropriação crítica desse imaginário, desideologizando o repertório poético de atualizações conservadoras. E a literatura comparada, nesta perspectiva, mais do que o estudo de dois ou mais escritores de diferentes literaturas, dois ou mais textos dispôs os lado a lado, se mostra campo fértil para a discussão de uma questão crítica mais abrangente e que envolve as duas culturas. Com o procedimento, partindo da literatura, poderíamos ainda imbricar, em suas formulações discursivas e do imaginário, discursos de outras áreas do conhecimento e de outros campos artísticos. A busca da especificidade conflui assim para a concepção de heterogeneidade constitutiva, malhas discursivas, também elas tendentes ao rompimento de fronteiras estáticas.

\section{A administração da diferença}

É importante reiterar, conforme estamos desenvolvendo, que o acesso à rede supranacional se faz num lócus enunciativo determinado, sem abstrações. Se um crítico literário tem seu contexto situacional numa universidade norte-americana, por exemplo, ele não pode desconsiderar o fato de que seu discurso não deixa de estar associado a estratégias hegemônicas desse país, que pode inclusive não apenas aceitar, mas também a promover a capitalização da diferença. Uma diferença evidentemente que se consubstancia em produtos, desde a imagem democrática do país hegemônico até a mercadorias mais diretamente comercializáveis. Haverá, além disso, um "reconhecimento" internacional da instituição onde esse crítico trabalha, o que certamente atrairá alunos, inclusive dos países nãohegemônicos. A partir dessa situação, serão criadas as condições para convênios interinstitucionais com esses países.

É provável que o fluxo cultural hegemônico, configurado em teorias e correntes críticas, poderá ter um entreposto associado. Se esse porto for efetivamente crítico, é de se presumir que veiculará fluxos de natureza diferente daqueles da estandardização que norteia a cultura de massa, mas suas práxis não deixarão de apresentar vetorização equivalente. Sem reconfigurações das redes discursivas intervenientes à situação do novo lócus, o porto corre o risco de ser no máximo uma particularidade de um desenho mais abrangente da administração da diferença. O lócus determinante do fluxo, no caso da sublocação, não deixa 
de estar no centro hegemônico. É próprio das estratégias de legitimação da hegemonia tolerar a diferença, desde que seja uma diferença administrada, quase sempre prevista e elaborada, enquanto possibilidade de abertura, desde o centro do fluxo. Tais observações valem tanto para o vestuário quanto para as modas críticas. Através de estratégias de convergência dessa modalidade de administração, a incorporação orgânica da diferença poderá inclusive constituir fator de dinamização da rede hegemônica.

As assimetrias dos fluxos, como se pode inferir, produzem formas de interações que não apenas estabelecem, mas também preservam situações de dependência. Há um reiterado descompasso entre os "nós" que desencadeiam fluxos dominantes e os demais pontos das redes que articulam. Em termos culturais, como também tecnológicos, criam-se assim situações de "atrasos" sistêmicos. Em consequiência, perpetua-se no imaginário a idéia de dependência e de um necessário ajuste às formulações que vêm de fora. Naquele horizonte externo, desenhado pelos meios de comunicação, está o modelo a ser imitado. Um ponto de chegada voltado para fora. Não um horizonte configurado a partir de carências e também das experiências que têm suas bases na sociedade e situação sociocultural do país, mas uma inclinação para um ajuste acrítico à última novidade, posta em circulação pelo mercado de bens culturais, processos de modelização associados à lógica de quem tem hegemonia em termos de poder simbólico.

Atualizações críticas, nesse sentido, não podem ignorar os cruzamentos discursivos de contextos situacionais provenientes das relações de pertencimento de sujeitos envolvidos em redes que produzem seus fluxos. Mesmo adotando atitudes como se estivessem em situações psicossociais de migrantes, eles não dialogam em abstrato, mas com culturas diferentes, provenientes de experiências históricas que têm suas singularidades. E estar nos EUA não é como estar no Brasil ou em qualquer outra parte do planeta, como aparece nos discursos tendentes à neutralização da diferença e à sublocação do mesmo. Se os óculos críticos advindos dessa circulação cultural podem aguçar a percepção, em função dessa mesma criticidade eles não podem implicar convergências ópticas inclinadas à preservação da continuada colonização do imaginário nas regiões ou países situados na periferia do capital.

Revista Crioula USP, $\mathrm{n}^{\circ}$ 17, junho de 2016 